\title{
Marketing technology in macroeconomics
}

\author{
Kenichi Tamegawa*
}

\begin{abstract}
In this paper, we incorporate a marketing technology into a dynamic stochastic general equilibrium model by assuming a matching friction for consumption. An improvement in matching can be interpreted as an increase in matching technology, which we call marketing technology because of similar properties. Using a simulation analysis, we confirm that a positive matching technology shock can increase output and consumption.
\end{abstract}

Keywords: DSGE modeling, Marketing, Matching friction

\section{Introduction}

The considerable progress in information technology (IT) since the late 1990s increased the productivity of goods and contributed to the IT boom in the economies of many countries in the 2000s. In economics, IT development is typically expressed as an increase in total factor productivity (TFP). This is a point of view from supply side of the economy. Jorgenson (2001) and Jorgenson et al. (2008) pointed out that nonfarm business productivity growth surged from 1997 to 2001 .

In addition to the supply side effects of IT, we can consider that IT also affects the demand side. Through web sites such as Amazon.com, for example, the Internet enables us to buy numerous goods instantaneously. A recent development in IT, the so-called Web 2.0, which includes social networking services such as Facebook, has enabled firms to contact individual consumers and promote their products. Recent developments in mobile phone technology, for example the iPhone, provide opportunities for matching consumers and products. This is reflected in the worldwide increase in Internet users (see Figure 1), which in turn increases opportunities for matching. In convenience, we call the technology, which enhances matching opportunity, "marketing technology," because it can easily match consumer needs with a firm's products and therefore resembles the concept of marketing. Broadly speaking, IT may enhance productivity as stated above. In this paper, however, we limit the scope of marketing technology to that which provides greater

Correspondence: tamegawa@kisc.meiji.ac.jp

School of Commerce, Meiji University, 1-1 Kanda-Surugadai, Chiyoda-ku, Tokyo 101-8301, Japan opportunities for sales, since studies for supply side technology like TFP are plentiful.

The way that production technology affects business cycles is well known ${ }^{1}$, but research on the effects of technology such as marketing technology on the macroeconomy has not yet been undertaken at least within the framework of macroeconomics. It is therefore quite interesting to investigate the effects of marketing technology. Our goals are as follows: first, to incorporate the marketing sector into an economic model; second, to assess the effects of the positive shock of marketing technology on the macroeconomy. First of all, we express marketing technology in an economic model by employing a matching or search friction in the goods market. Researchers have frequently employed this assumption in the labor market on the basis of Mortensen and Pissarides (1994). Adopting the matching friction suits our purpose because progress in marketing technology can be modeled as a reduction of matching friction between consumers and firms.

To accomplish the second goal, we use a dynamic stochastic general equilibrium (DSGE) model, which is a useful tool in analyzing the macro economy. The model consists of identity equations and behavioral equations that are derived from agents' optimization problems ${ }^{2}$. Our model is constructed on the basis of a standard real business cycle (RBC) model as described in King et al. $(1988)^{3}$. Of course, it can easily be extended to a New Keynesian model by adding a sticky price assumption, as used in Christiano et al. (2005).

In this paper, we show the effects of marketing technology by performing a numerical simulation. The main result is a positive response of output, which occurs

\section{Springer}

(c) 2012 Tamegawa; licensee Springer. This is an Open Access article distributed under the terms of the Creative Commons Attribution License (http://creativecommons.org/licenses/by/2.0), which permits unrestricted use, distribution, and reproduction in any medium, provided the original work is properly cited. 


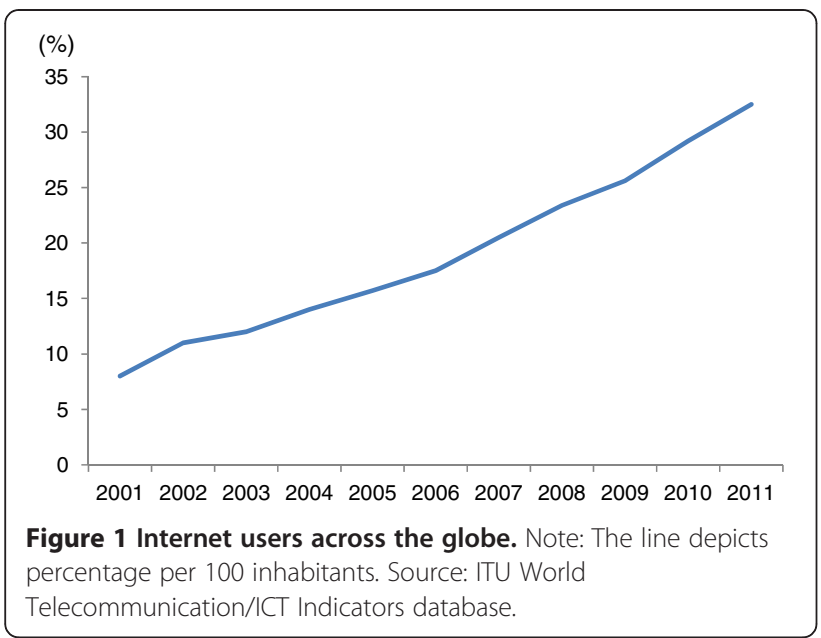

because progress in marketing technology can increase matched consumption. In our settings, the sudden increase in households' consumption provides an incentive to work more to smooth out the consumption path. Similar to increases in TFP, developments in IT technology that affect the demand side can also increase output and therefore income.

The remainder of our paper is organized as follows. Section 2 explains the key equation, which plays an important role in this paper. Section 3 constructs our model. Section 4 presents a simulation analysis of marketing technology. Section 5 discusses how incorporating the marketing sector into a DSGE model alters the model's responses to shocks from other marketing technologies. Section 5 concludes the paper.

\section{Matching friction for consumption}

This section explains the key equation of our model: matching friction. Suppose that a consumer has a consumption plan, denoted by $\mathrm{C}_{\mathrm{t}}$, and that firms use some amount of resources denoted by $a_{t}$ to advertise their goods. We then assume that consumer needs are met through the following Cobb-Douglas type matching function:

$$
C_{t}^{m}=e^{Z_{t}^{C}}\left(C_{t}\right)^{\gamma}\left(a_{t}\right)^{1-\gamma}
$$

where $C_{t}^{m}$ represents matched consumption. In the above equation, an increase in $Z_{t}^{C}$ implies that the matching opportunity becomes bigger. We therefore call it marketing technology. High planned consumption and advertisement also facilitate the matching. The motivation of assuming Eq (1) stems from the study of matching friction for the labor market introduced by Mortensen and Pissarides (1994) ${ }^{4}$. In their study, labor matching results from a combination of vacancies offered by firms and the labor force provided by households. This assumption is also useful in a consumption matching framework.

For the following simulation, we assume that $\log Z_{t}^{C}$ follows an $\operatorname{AR}(1)$ process. Note that under this setting, $\theta_{t} \equiv C_{t}^{m} / C_{t}=Z_{t}^{C}\left(a_{t} / C_{t}\right)^{1-\gamma}$ can be interpreted as a matching probability. Moreover, in Eq (1), If $\gamma=1$ and $Z_{t}^{C} \equiv 0$, the model constructed below is reduced to a standard RBC model.

\section{Model}

In our model, firms have a marketing sector and a production sector, households live infinitely, and there exists a the government. The population is normalized to 1 . We begin by explaining the matching friction.

\section{Firms: Production sector}

Firms in the production sector have the following CobbDouglas production function:

$$
Y_{t}=e^{Z_{t}^{Y}}\left(K_{t}\right)^{\alpha}\left(h_{t}\right)^{1-\alpha},
$$

where $Y_{t}$ represents output; $K_{t}$, capital stock; $h_{t}$, hours worked; And $\log Z_{t}^{Y}$, a productivity shock with mean 0 . With this technology of production, firms' gross profits are as follows:

$$
Y_{t}-a_{t}-w_{t} h_{t}-\left(R_{t}-1+\delta\right) K_{t},
$$

where $a_{t}$ is the goods used in advertising. The net output for firms is therefore $Y_{t}-a_{t}$. The first-order condition for profits maximization yields

$$
w_{t}=(1-\alpha) \frac{Y_{t}}{h_{t}}
$$

The gross rental rate is as follows:

$$
R_{t}=\alpha \frac{Y_{t}}{K_{t}}+1-\delta
$$

\section{Firms: Marketing sector}

The marketing sector receives $a_{t}$ from the production sector and conducts marketing activities. Consequently, their goods meet consumer needs through the consumption matching function. As stated above, to conduct this activity, we assume that the marketing sector needs $a_{t}$. The marketing sector demands $a_{t}$ to maximize $C_{t}^{m}-a_{t}$. The first-order condition is

$$
(1-\gamma) \frac{C_{t}^{m}}{a_{t}}=1
$$

Note that $C_{t}^{m}-a_{t}$ is not profit but merely a hypothetical objective function. 


\section{Households}

This subsection explains the aggregated behavior of households. First note that households are subject to the following inter-temporal budget constraint ${ }^{5}$ :

$$
D_{t+1}=R_{t} D_{t}+w_{t} h_{t}-\theta_{t} C_{t}-T_{t},
$$

where $D_{t}$ represents financial assets and $T_{t}$ denotes lump-sum tax. Assuming that temporal utility is $\log \theta_{t} C_{t}$, households decide their planned consumption and labor supply by maximizing the following utility function, given $\left\{\theta_{\mathrm{t}}\right\}$ :

$$
E_{0}\left[\sum_{t=0}^{\infty} \beta^{t}\left\{\log \theta_{t} C_{t}+\tau \log \left(1-h_{t}\right)\right\}\right],
$$

where $\beta$ represents a discount rate. The first-order conditions are

$$
\begin{aligned}
& \frac{1}{C_{t}}=E_{t}\left[\frac{\beta R_{t+1}}{C_{t+1}}\right], \\
& \frac{\tau h_{t}}{1-h_{t}}=\frac{w_{t}}{C_{t}} .
\end{aligned}
$$

Note that the consumption path is independent $\left\{\theta_{t}\right\}$ as shown in Eq (8).

\section{Equilibrium condition}

Assuming that capital stock is accumulated As $K_{t+1}=$ $(1-\delta) K_{t}+I_{t}$ with a depreciation rate of $\delta$ and an investment of $I_{t}$ and that the primary balance for the government is always zero, an equilibrium condition $K_{t+1}=D_{t+1}$ yields

$$
Y_{t}=C_{t}^{m}+I_{t}+G_{t}+a_{t}
$$

where $G_{t}$ represents government expenditure (which is equal to $T_{t}$ ).

For convenience of understanding the flow of goods, we provide Figure 2. First, firms produce goods using labor and capital goods that are provided from households. Households (consumers) consume the goods and

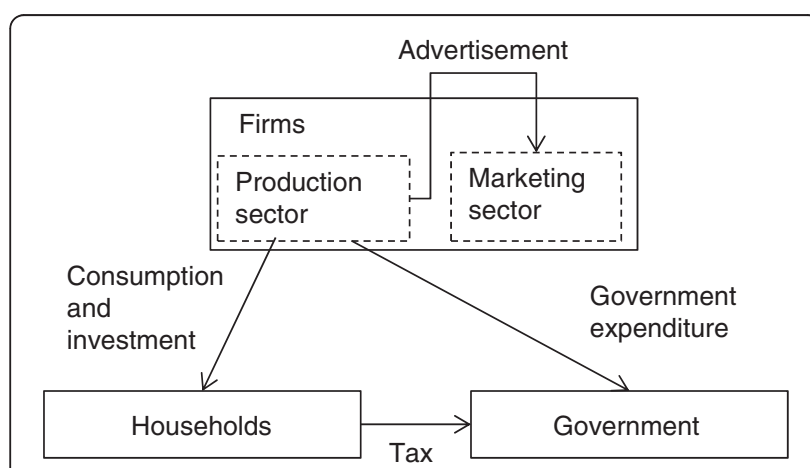

Figure 2 Flow of Goods. pay tax to government. Advertisement is implemented through the goods that firms produce; in other words, advertisements are own consumption for firms.

\section{Simulation analysis}

How does the model behave against a positive marketing shock? First, since this shock provides a matching opportunity, matched consumption increases; consequently, saving decreases. This decrease in turn raises the rental rate and provides an incentive to work more. Therefore, output also increases. Planned consumption nevertheless decreases because rental rate increases. Although a matching improvement increases output over several periods, consumption later decreases because of a consumption-smoothing motive. On the other hand, an increase in saving reduces the rental rate and causes a decrease in the labor supply also decreases. Intuitively speaking, an increase in matching technology raises consumption; this forces households to work more to compensate for the increased consumption. As a result, output increases.

To confirm the above theoretical conjecture, we linearize and simulate the model. The parameter settings are $\left[\alpha \beta \delta C^{m} h\right]=\left[\begin{array}{lllll}1 / 3 & 0.99 & 0.02 & 0.6 & 1 / 3\end{array}\right]$, where $C^{m}$ and $h$ denote the steady-state values. For $\gamma$, we consider $\gamma=$ 0.95 and $\gamma=0.5$. A persistency parameter for $\log Z_{t}^{C}$ is 0.9 . The output share of advertising is 0.01 in the steady state. In Figure 3, we show impulse responses to the one percent shock for $\log Z_{t}^{C}$. In the case of $\gamma=0.5$, since consumption matching is strongly affected by advertising, responses to the marketing shock are volatile.

As shown above, while a positive marketing shock can raise output, it decreases investment. This phenomenon seems to contrast with the experience of the late1990s. In the actual economy, however, IT can increase TFP. We can therefore consider that for this period, investment increases through a positive TFP shock. Of course, since there is a possibility that matching technology increase investment in the actual economy, careful empirical research is needed.

\section{Discussion: Consumption matching friction neutrality}

How does the consumption matching friction alter responses to a supply or demand shock other than by matching technology relative to a standard RBC model? In a linearized model, the answer is that the friction does not alter the other shock responses. This is because households know how much their needs are matched by goods produced by firms; in other words, they know the matching probability $\theta_{t}$. Households then know the amount of goods to consume under a given shock even though matching friction is assumed. This implies that $C_{t}^{m}$ does not depend on the value of $\gamma$. Regardless of the 


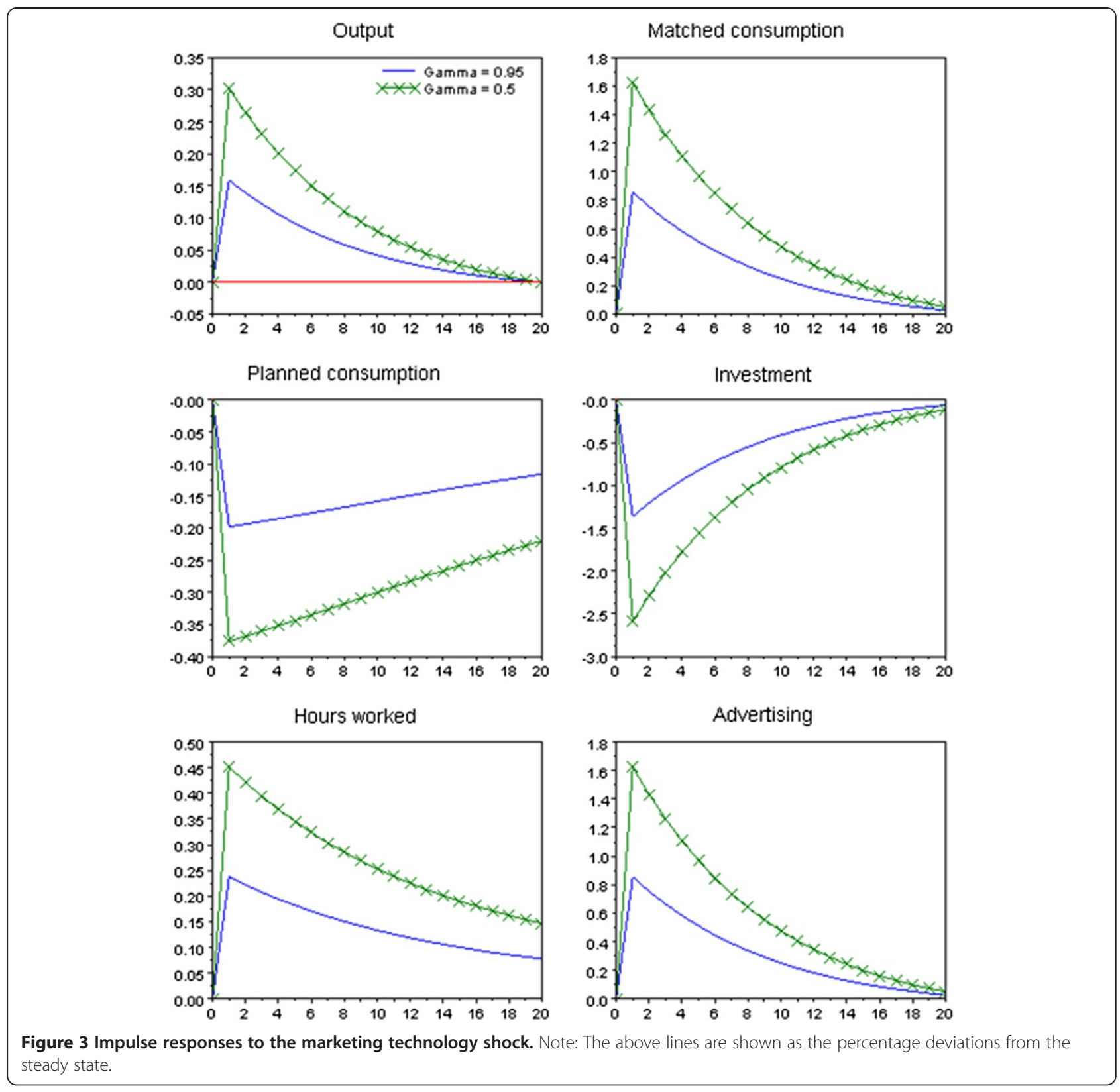

value of $\gamma$, the responses to shocks other than the marketing technology shock are not altered.

This neutrality is not a drawback but an attraction from the empirical view point. Incorporating a consumption matching friction into a DSGE model may improve the results of empirical analyses such as that of Smets and Wouters (2003), since adding this assumption does not harm the model properties. Further, marketing technology is considered to be a new structural shock. With this new shock, the model can allow for richer dynamics, which helps reduce the problem of the degree of stochastic singularity (see Ruge-Murcia, 2007 and Tovar, 2009).

\section{Concluding remarks}

In this paper, we incorporated a marketing technology into a DSGE model by assuming a matching friction for consumption. The improvement in matching could be interpreted as an increase in matching technology. Using a simulation analysis, we confirmed that positive matching technology shock can raise output and consumption.

Further implications of what this paper has demonstrated in theoretical results need to be assessed through empirical studies. Fortunately, methods of empirical research on the basis of a DSGE model, for example, the method that Smets and Wouters (2003) used, are now becoming more familiar to economists. To investigate the 
effects of marketing technology on the economy of the late 1990s is quite interesting, but this is left for the future.

\section{Endnotes}

${ }^{1}$ For example, see Romer (2011).

${ }^{2}$ The motivation for using the DSGE models in analyzing the macroeconomy is to avoid the famous critique by Lucas (1976): a model has to be described such that it is invariant to exogenous shock.

${ }^{3}$ Famous DSGE models are surveyed in Tovar (2009) and McCandless (2008).

${ }^{4}$ There are many studies that investigate the effects of labor market friction on business cycles. For example, see Shimer (2010).

${ }^{5}$ This expression of budget constraint can be archived from the law of large numbers for $\theta_{t}$.

\section{Abbreviations}

DSGE: Dynamic stochastic general equilibrium; IT: Information technology; TFP: Total factor productivity; RBC: Real business cycle; AR: Auto regression.

\section{Competing interests}

The author declares that he has no competing interests.

\section{Authors' contributions}

$\mathrm{KT}$ carried out constructing the model, conducted the simulation analysis and drafted the manuscript. All authors read and approved the final manuscript.

\section{Acknowledgements}

I am grateful to anonymous referees and Shin Fukuda for their helpful comments.

Received: 25 July 2012 Accepted: 27 September 2012

Published: 4 October 2012

\section{References}

Christiano L, Eichenbaum M, Evans C (2005) Nominal rigidities and the dynamic effects of a shock to monetary policy. J Polit Econ 113:1-45

Jorgenson DW (2001) Information Technology and the U.S. Economy. Am Econ Rev 91:1-32

Jorgenson DW, Ho MS, Stiroh KJ (2008) A Retrospective Look at the U.S Productivity Growth Resurgence. J Econ Perspect 22(1):3-24

King R, Plosser C, Rebelo S (1988) Production, growth and business cycles I: the basic neoclassical model. J Monet Econ 21:195-232

Lucas R (1976) Econometric policy evaluation: a critique. Carnegie-Rochester Conf Ser Public Policy 1:19-46

McCandless G (2008) The ABCs of RBCs. Harvard University Press, Cambridge

Mortensen T, Pissarides C (1994) Job creation and job destruction in the theory of unemployment. Rev Econ Stud 61:397-415

Romer D (2011) Advanced Macroeconomics. McGraw-Hill, Irwin

Ruge-Murcia FJ (2007) Methods to estimate dynamic stochastic general equilibrium models. J Econ Dyn Control 31:2599-2636

Shimer R (2010) Labor Markets and Business Cycles. Princeton University Press, Princeton

Smets F, Wouters R (2003) An estimated dynamic stochastic general equilibrium model of the Euro area. J Eur Econ Assoc 20:1123-1175

Tovar CE (2009) DSGE Models and Central Banks. Economics: The Open-Access, Open-Assessment E-Journal 3, http://dx.doi.org/10.5018/economics-ejournal. ja.2009-16

doi:10.1186/2193-1801-1-28

Cite this article as: Tamegawa: Marketing technology in macroeconomics. SpringerPlus 2012 1:28.

\section{Submit your manuscript to a SpringerOpen ${ }^{\circ}$ journal and benefit from:}

- Convenient online submission

- Rigorous peer review

- Immediate publication on acceptance

- Open access: articles freely available online

- High visibility within the field

- Retaining the copyright to your article

Submit your next manuscript at $\gg$ springeropen.com 